\title{
eLyra
}

\section{A poetisa e sua mestra}

\section{Sofia de Sousa Silva \\ Universidade Federal do Rio de Janeiro}

Resumo: No início dos anos 2000, Adília Lopes afirmava que os seus modelos de escrita eram Sylvia Plath, Ruy Belo e Sophia de Mello Breyner Andresen. Esta última virá a ser referida, numa entrevista, como sua mestra, o que explica que o diálogo com Sophia seja uma constante na obra dessa autora ao longo dos anos. Inicialmente marcado por uma atitude de contraposição entre um ideal clássico (defendido por Sophia) e a defesa da imperfeição (por parte de Adília Lopes), esse diálogo se fundamenta numa busca comum do rigor e da depuração da língua, que em cada uma leva a diferentes concepções do que seja a palavra justa.

Palavras-chave: Mestra, Precisão, Liberdade

\begin{abstract}
In the early 2000s, Adília Lopes claimed that her writing models were Sylvia Plath, Ruy Belo and Sophia de Mello Breyner Andresen. The latter will be referred in an interview as her master, which explains that the dialogue with Sophia is constant in Adília Lopes's work over the years. Initially marked by an attitude of opposition between a classical ideal (defended by Sophia) and the defense of imperfection (by Adília Lopes), this dialogue is based on a common search for the rigor and purification of language, which in each leads to different conceptions of the accurate word.
\end{abstract}

Keywords: Master, Accuracy, Freedom 
Sophia de Mello Breyner Andresen é decerto um dos nomes mais convocados para o diálogo por Adília Lopes. Esse fato é significativo numa poesia intensamente marcada pela citação de obras literárias, musicais, plásticas, cinematográficas, entre outras. Na primeira grande reunião de poemas que publicou (Obra, Lisboa, Mariposa Azual), no ano 2000, é Sophia, ao lado de Agustina Bessa-Luís, autora de uma das duas epígrafes. Os nomes das duas escritoras comparecem ali num gesto que pode ser lido como o de reivindicação de uma linhagem literária em que as mulheres ocupam um papel de relevo.

Essa relação reivindicada com Sophia comparece, nos primeiros livros, por exemplo, numa citação com caráter paródico do poema "As pessoas sensíveis" no livro Maria Cristina Martins:

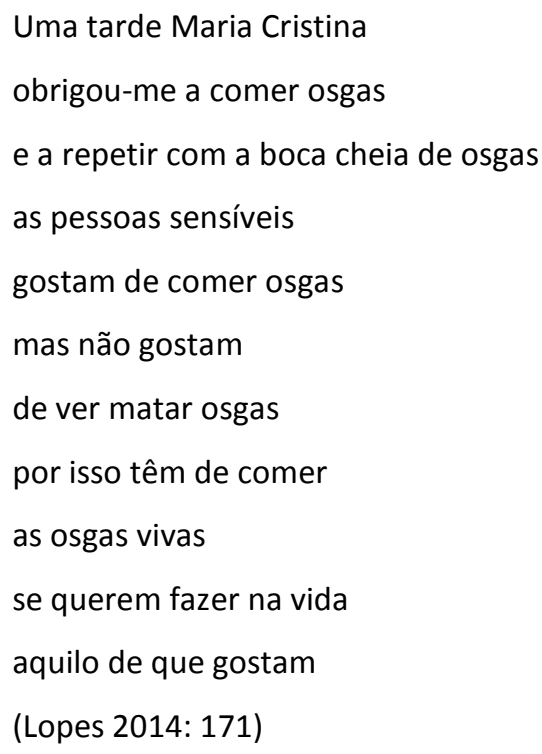

A célebre quadra inicial do poema de Livro sexto diz: "As pessoas sensíveis não são capazes/ De matar galinhas/ Porém são capazes/ De comer galinhas" (Andresen 2015: 485). A substituição das galinhas, animal que com frequência faz parte da alimentação em todo o mundo, pelas osgas, animal que frequentemente causa repugnância ao simples olhar (que dirá ao tato ou ao paladar), assim como a solução inesperada do final, perturbam o tom de denúncia do poema de Sophia, criando ainda um efeito de humor.

Mas, coincidindo com o momento em que começa a receber maior atenção crítica sendo chamada a dar entrevistas e depoimentos -, no início dos anos 2000, Adília Lopes passa a atribuir enorme relevância ao nome de Sophia, dizendo: "As minhas grandes 
influências, que admito e reconheço, são Sophia, Ruy Belo e Sylvia Plath. Foi com eles que comecei a escrever e é com eles e por eles que continuo a escrever e a ler." (Lopes 2004: 30).

Em particular a "Arte poética IV" passa a ser referida com insistência. Numa entrevista concedida à revista brasileira de poesia Inimigo Rumor, diz:

Os textos em que melhor reconheço a minha maneira de fazer poesia são a "Arte Poética IV" de Sophia de Mello Breyner Andresen (incluída em Dual) e "Bresson, o mergulho" de Nuno Bragança (incluído no catálogo do ciclo Bresson, Fundação Calouste Gulbenkian, 1978). (Lopes 2001: 23)

Alguns anos depois, num depoimento à Relâmpago: Revista de Poesia, a referência se torna mais enfática:

Escrevo sempre por inspiração e num impulso. Sophia de Mello Breyner Andresen diz muito melhor do que eu o que tenho a dizer sobre o que é e como é para mim escrever um poema. Está tudo em "Arte Poética IV" de Dual. (Lopes 2004: 29)

Finalmente, numa entrevista em 2007, chega a uma síntese: "Sophia é a minha mestra, o meu modelo de bem escrever português" (Lopes 2007: 157).

Na primeira década do século XXI, parecia surpreendente falar numa proximidade entre Adília Lopes e Sophia. Não se pensava então num parentesco entre as duas autoras, que aparentavam distância em suas poéticas e suas preocupações, e, sobretudo, em sua linguagem. ${ }^{1}$ No entanto, a presença intertextual de Sophia já se fazia sentir com frequência na obra de Adília, ainda que pudesse ser minimizada, pois, sob certo aspecto, a relação com a "mestra" parecia muito marcada pela contraposição. E em particular contra as ideias que os adjetivos limpo, liso, branco, inteiro que habitam a poesia de Sophia poderiam traduzir.

Em Sophia, as ideias de inteireza e de beleza se desdobram para um sentido ético e ontológico. Num poema que tem como personagem um pescador, este é "Irmão limpo das coisas", e "[...] está inteiro em sua vida” (Andresen 2015: 433, grifos nossos).

A beleza é também promessa de realização, talvez até política:

Sua beleza à força de ser bela

Promete mais do que prazer 
Promete um mundo mais inteiro e mais real

Como pátria do ser

(Andresen 2015: 660)

Em resumo, poderíamos aplicar à sua própria poesia os versos que dizem:

Esta foi sua empresa: reencontrar o limpo

Do dia primordial. Reencontrar a inteireza

Reencontrar o acordo livre e justo

(Andresen 2015: 698)

Os ideais da arte clássica, sobre os quais Sophia escreve em O Nu na Antiguidade Clássica, de certo modo norteiam a sua própria poética. É o que se nota se confrontarmos com os versos acima, por exemplo, este fragmento:

[...] em frente do real o olhar grego escolhe e quer escolher. A obra é o resultado de uma análise do corpo humano mas que deixa de lado tudo quanto é acidental ou individual e tudo quanto não encontrou ou perdeu a plenitude da sua forma. Assim o artista clássico só muito raramente representa a criança pois ela ainda não é perfeita e também raramente representa o velho porque ele não possui plenamente a sua própria forma. [...] (Andresen 1992: 89)

É justamente essa poética que é criticada por Adília Lopes. A noção moderna da forma justa, que articularia justeza e justiça propondo uma espécie de concerto entre os seres humanos, tem no poema "Brasília", de Geografia, o seu mais acabado exemplo. Ora, essa noção é denunciada como um risco inerente à passagem de um ideal artístico para um ideal político, onde a ideia de ordem carrega consigo o risco da aniquilação do outro. Se Sophia celebra a cidade "ordenada e clara como um pensamento" (Andresen 2015: 566), um poema de César a César vem nos lembrar de que:

\author{
A ordem \\ pode ser \\ a maior \\ desordem \\ (Lopes 2014: 503) $)^{2}$
}


Esse problema se torna mais evidente quando se toca no tema da doença. Se em seu poema "A forma justa", Sophia diz: "Se nada adoecer a própria forma é justa" (Andresen 2015: 710), a doença será tema recorrente tanto na poesia de Adília Lopes como nas entrevistas e depoimentos que dá.

A preocupação com o caráter excludente dessa noção tão moderna de forma justa que Sophia endossa é decerto relevante na obra de Adília, que se dedica, por exemplo, a escrever sobre o "mau poeta", atormentado pelo juízo severo que Diderot (ou quem fala por ele em Jacques le Fataliste) faz de seus poemas e termina por enlouquecer repetindo para si mesmo a proibição de Diderot (Cf. Lopes 2014: 43).

A exclusão da doença do projeto da forma justa também parece perturbar o sentimento ético desta poesia, que se torna um espaço para acolher o mongolóide e o atrasado mental (Cf. Lopes 2014: 193), assim como todas as dimensões do corpo.

Em Irmã barata, irmã batata, um fragmento - aliás exemplar do seu modo de escrita, apropriando-se sempre de palavras ouvidas ou lidas - parece visar diretamente a obra da mestra, dizendo:

O sexo não é porco nem deixa de ser. Nada na vida dá garantia de ser limpo liso nu inteiro. Nem aquele quartinho em que está o eu, um quartinho que seja seu, porque mesmo o eu é o outro. (Lopes 2014: 410)

A nota inicial ao livro $A$ mulher-a-dias afirmava: "De resto, os meus textos são políticos, de intervenção, cerzidos com a minha vida." (Lopes 2014: 443). Esse caráter de intervenção reivindicado pela poesia de Adília (contra a exclusão, contra os ideais aprisionadores, contra a lógica economicista, entre outras bandeiras que podemos identificar), por um lado, parece aproximá-la de Sophia, que, de diversas maneiras, empenhou a sua palavra de poeta e de cidadã no esforço de construção de um mundo justo, mas o engajamento aqui dirige-se inclusive contra certa moral do poema de Sophia, em particular contra o que nela pode haver de um desejo de ordem em última análise incompatível com a vida.

Por isso, à "Meditação do Duque de Gandia sobre a morte de Isabel de Portugal" (Andresen 2015: 374), Adília contrapõe a “Meditação sobre meditação" (Lopes 2014: 469) e 
no lugar do "Terror de te amar num sítio tão frágil como o mundo" (Andresen 2015: 237), propõe que o mundo é um matadouro disfarçado, mas que apesar disso "Gosto de gostar de si/num sítio assim" (Lopes 2014: 340), respondendo simultaneamente a Sophia e a Fernando Pessoa-Álvaro de Campos.

Por que, então, Sophia seria a mestra, o seu modelo de bem escrever português?

Talvez a resposta se encontre precisamente no português de Sophia. É pela sua linguagem que se pode dizer da poesia de Sophia o mesmo que ela disse a respeito da escultura clássica: "Por isso quase sempre as formas da escultura criam ao seu redor uma luz de praia" (Andresen 1992: 29).

A língua de Sophia dá a cada palavra um contorno preciso, um sentido de renovação, de ar fresco. Como isso é feito não é simples de definir, mas tem decerto a ver com o seu trabalho com a língua, com a sua atenção ao peso das sílabas, como, aliás, ela diz num ensaio sobre Camões, passando rapidamente da forma justa da palavra para a justiça:

Creio profundamente que toda a arte é didáctica, creio que só a arte é didáctica.

Camões propõe-nos palavras ditas sílaba por sílaba. Propõe-nos a contínua acusação do gosto da cobiça e da vileza, a contínua acusação da surdez, da asfixia, do opaco. Ensina-nos a não aceitar o ensombramento que nos rói. Ensina-nos uma atitude de crítica constante. Ensina-nos a procurar a diversidade do mundo em que estamos. Propõe-nos uma imagem exigente de nós próprios que nunca mais nos deixará sossegar. (Andresen 1981: 164; grifos nossos)

Estas palavras ditas sílaba por sílaba ${ }^{3}$ são o que se nota, por exemplo, num poema em que se ouve um eco da llha dos Amores camoniana e no qual se fala de uma "branca praia cor de rosas" (Andresen 2015: 721). A simples substituição do cor de rosa por "cor de rosas" na descrição da praia faz com que se recupere que no nome da cor está uma flor. A rosa volta a aparecer.

O mesmo se pode observar na dedicatória que Sophia escreve para sua amiga Helena Lanari, e que Eucanaã Ferraz reproduz em seu artigo "Ouvir o poema": "Para a Helena Lanari, no dia em que vimos o Cabo Frio, que foi um dia maravilhoso" (Andresen apud Ferraz 2009: 41)

Ninguém que conheça a cidade de Cabo Frio, no estado do Rio de Janeiro, usaria o verbo ver e nem o artigo definido $o$ antes desse topônimo. A forma corrente da expressão 
seria "no dia em que fomos a Cabo Frio". A substituição de ir por ver faz com que de fato o leitor veja que o nome da cidade contém o nome de um acidente geográfico, há muito esquecido. O cabo é redescoberto por obra da língua de Sophia.

Em recente depoimento sobre a mestra, Adília diz que aprendeu com ela que "O mundo do poema é limpo e rigoroso. Nada de coisas farfalhudas, nada de aldrabices" (Lopes 2019). Estamos em crer que é sobretudo ao rigor e à depuração da língua de Sophia que Adília se refere quando a chama "modelo de bem escrever português". Adília diz que escreve "apesar de tudo", "a pesar tudo" (Lopes 2016: 86). E, no mesmo livro chega a dizer “A minha poesia é didáctica" (Lopes 2016: 121), ecoando o ensaio de Sophia sobre Camões. A sua preocupação com o peso das palavras, com a precisão da linguagem e com a crescente corrupção desta pelo discurso pseudocientífico ou pseudo-higiênico (poderíamos dizer) se faz notar com força em seus livros mais recentes. Num poema do livro $Z / S$, publicado em 2016, diz:

NA CASA DE CORRECÇÃO OU NA CASA DE PASSE

Não diga prazer, diga satisfação.

Não diga rapazes, diga colegas masculinos.

Não diga sex-appeal, diga atractivos sexuais.

$8 / 12 / 15$

(Lopes 2016: 21)

A substituição de palavras por seus equivalentes "neutralizados", "cientificizados" retira-Ihes o vigor expressivo e, no caso em foco, retira-lhes, em particular, a tensão sexual. Como se se quisesse fazer do sexo "não o sexo mas um céu residencial" (Neto Jorge 2001: $190)^{4}$.

Na contramão desse movimento, fiel à dicção rigorosa de Sophia e à consciência de que o poema não admite paráfrase, Adília prefere chamar as coisas pelo nome que têm na tradição, pelo menos desde o século XIII. Como neste poema de Sete rios entre campos, que 
explora ainda as semelhanças fônicas entre os dois verbos empregados, presentes na poesia da península Ibérica desde as suas primeiras manifestações conhecidas:

\author{
Quem fode \\ fode \\ fode \\ quem pode \\ (Lopes 2014: 332)
}

Por mais paradoxal que pareça, já que Sophia nunca usou palavrões em seus poemas e se pronuncia mesmo contrária a isso em carta a Jorge de Sena, ${ }^{5}$ quando Adília emprega palavrões em seus poemas mostra a sua fidelidade à mestra. É a própria quem o explica, numa crônica:

Eu sei que pode parecer estranho, esquisito, a alguns olhos (ou ouvidos) que uma pessoa como eu, que escreve palavras como "merda", goste de livros em que se escreve a palavra "Deus". Pronuncio muito raramente palavrões e termos de calão. Ultimamente, já há uns anos, uso muitos palavrões nos meus poemas. Alguns desses palavrões só os conheço por via erudita (romances de Nuno Bragança e de Almeida Faria, por exemplo) e nem sei ao certo como se pronunciam. Sophia de Mello Breyner Andresen escreveu "Aquele que vê o fenómeno quer ver todo o fenómeno" e, no mesmo texto, "a poesia é uma moral” (in "Arte poética III").

A minha mãe contava que, no Colégio de $\mathrm{S}$. José, nos anos 40 do século passado, na Rua José Estêvão em Lisboa, uma freira dizia a outra freira que tinha pronunciado "merda": "Ó irmã, diga "arroz" que também tem cinco letras". Pois, mas não é a mesma coisa. Para já, não é a mesma coisa foneticamente. Não quero que nenhuma palavra baixe a cabeça no meio da frase. Assim agrado e desagrado a gregos e troianos. Do ponto de vista linguístico, científico, filológico, acho isto correcto, honesto. Talvez isto seja demasiado rebuscado e complicado, um paradoxo, mas é até, e sobretudo, do ponto de vista da moral que eu acho isto certo. (Lopes 2002)

Afinal, parece que é ainda o ideal de forma justa que se vê aqui revisitado. Há uma implicação moral numa escolha linguística, filológica. A intervenção desejada por esta poesia, o seu "didatismo", vem não só do que diz mas do como diz.

A reflexão sobre as relações entre mestres e discípulos pode ser observada para além desse caso específico, manifestando-se também em outras artes, como, por exemplo, na 
música. Ao comentar as vozes masculinas no canto brasileiro, num programa da Rádio Batuta, o cantor e compositor Alfredo Del-Penho explica que os caminhos abertos por um cantor, as inovações que faz na maneira de cantar, por mais inventivas e até desconcertantes que sejam, como no caso de João Gilberto, nunca representam qualquer tipo de fechamento ou limitação para os cantores que o sucederão, mas sim, necessariamente, uma abertura. A influência de um cantor não se faz sentir apenas naqueles que reproduzem um determinado ornamento usado por ele, afirma Del-Penho, mas, quando um cantor faz isso, quando abre um caminho novo, o que reverbera nos outros não é só a possibilidade de imitação, mas uma aproximação com a liberdade.

O modo como Adília recebe a lição de Sophia talvez possa ser pensado nos termos usados por Alfredo Del-Penho. Afinal, uma mestra não ensina a imitar, ensina a sua própria liberdade. 


\section{NOTAS}

${ }^{1}$ Em Almadilha: ensaios sobre Sophia de Mello Breyner Andresen, Federico Bertolazzi estuda as referências de Adília a Sophia através da ligação de ambas com uma quadra de Teixeira de Pascoaes e reconhece em Adília um “dizer, limpo e claro," que ela partilha com Sophia. (Bertolazzi 2019: 161).

2 Esta questão é discutida em Silva 2013.

${ }^{3}$ Ver a esse respeito o ensaio de Rosa Maria Martelo, “Sophia e o fio de sílabas" (Martelo 2010).

${ }^{4}$ Recanto 10

$[\ldots]$

logo as patas do Anjo se erguiam

sobre o sexo

esmagava-o sorvia-o ilusionava-o

para que parecesse não o sexo

para que parecesse um céu

residencial

$[\ldots]$

(Neto Jorge 2001: 190)

5 “A fidelidade à imanência tornou-se pecado. O homem deixou de ser um com seu corpo, e com a mulher. As palavras que significam sexo transformaram-se em palavrões - não significam sexo mas não-identificação do ser como sexo. Significam divórcio. Usá-las é aceitar esse divórcio." (Breyner 2010: 139) 


\section{Bibliografia}

Andresen, Sophia de Mello Breyner (2015), Obra Poética, Lisboa, Assírio \& Alvim.

-- (1992) O Nu na Antiguidade Clássica, 3ạ ed., Lisboa, Caminho.

-- (1981), Luís de Camões: ensombramento e descobrimento, in Poemas Escolhidos, Lisboa, Círculo de Leitores. [Primeira publicação: Cadernos de Literatura, n. 5, Coimbra, 1980.]

Bertolazzi, Federico (2019), Almadilha. Ensaios sobre Sophia de Mello Breyner Andresen, Lisboa, Documenta.

Breyner, Sophia de Mello/ Sena, Jorge de (2010), Correspondência: 1959-1978, 3ạ edição, Lisboa, Guerra e Paz.

Del-Penho, Alfredo (2015), "Alfredo Del-Penho e as vozes do Brasil”, apresentação Joaquim Ferreira dos Santos, 28 de agosto de 2015, Rádio Batuta, $<$ https://radiobatuta.com.br/programa/alfredo-del-penho-e-as-vozes-do-brasil2/\#.XZY1RapXilg.gmail> (último acesso em 03/09/2019).

Ferraz, Eucanaã (2001), Ouvir o poema, Relâmpago. Revista de Poesia, 9, Outubro de 2001: 31-48.

Lopes, Adília (2001), Entrevista, Inimigo Rumor. Revista de Poesia, 10, Rio de Janeiro, 7 letras, maio de 2001.

-- (2002), “Gn 4, 9-10”, Público, 21 de abril de 2002, < http://www.publico.pt/2002/04/22/ jornal/gn-4-910-169737> (último acesso em 28/08/2019)

-- (2004), [Resposta à pergunta] Como se faz um poema?, Relâmpago, 14, Lisboa, Fundação Luís Miguel Nava, abril de 2004.

-- (2007), Entrevista, in Silva, Sofia de Sousa, Reparar Brechas. A relação entre as artes poéticas de Sophia de Mello Breyner Andresen e Adília Lopes e a tradição moderna, Tese de Doutorado, Pontifícia Universidade Católica do Rio de Janeiro.

-- (2014), Dobra. Poesia reunida, 2ª ed., Lisboa, Assírio \& Alvim. 
-- (2016), Z/S, Lisboa, Averno.

-- (2019) “Adília sobre Sophia”, Centenário de Sophia de Mello Breyner Andresen, Lisboa, Fundação Calouste Gulbenkian, 16 de maio de 2019, https://youtu.be/7MivdxyEeP4 (último acesso em 01/09/2019).

Martelo, Rosa Maria (2010), Sophia e o fio de sílabas in A Forma Informe. Leituras de poesia, Lisboa, Assírio \& Alvim, p. 21-34.

Neto Jorge, Luiza (2001), Poesia: 1960-1989, 2a edição, org. e prefácio Fernando Cabral Martins, Lisboa, Assírio \& Alvim.

Silva, Sofia de Sousa (2013) Reparar brechas: uma possível relação entre Sophia de Mello Breyner Andresen e Adília Lopes, in Sophia de Mello Breyner Andresen. Actas do Colóquio Internacional, org. Maria Andresen de Sousa Tavares; Centro Nacional de Cultura, Porto, Porto Editora, p. 263-269.

Sofia de Sousa Silva é professora de Literatura Portuguesa da Universidade Federal do Rio de Janeiro desde 2010, tendo antes lecionado na Universidade Federal de São Paulo e na PUC-Rio. Tem mestrado e doutorado pela PUC-Rio, com tese sobre as obras de Sophia de Mello Breyner Andresen e de Adília Lopes. Em 2018, desenvolveu pesquisa de pósdoutorado na Universidade do Porto, em Portugal, com a qual mantém intercâmbio como pesquisadora do Instituto de Literatura Comparada Margarida Losa desde 2015 e membro da rede internacional de pesquisa Lyra Compoetics. Publicou Fernando Pessoa: para descobrir, conhecer e amar (Rio de Janeiro, Bazar do Tempo, 2016) e organizou e posfaciou Aqui Estão as Minhas Contas: Antologia poética de Adília Lopes (Rio de Janeiro, Bazar do Tempo, 2019). 